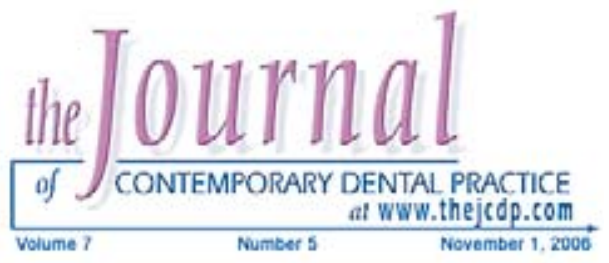

\title{
Effects of Repeated Fluoride Varnish Application on Different Restorative Surfaces
}

\author{
Fouad S. Salama, BDS, MS; K. Marche' Schulte, DDS; \\ Michael F. Iseman, DDS; John W. Reinhardt, DDS, MS, MPH
}

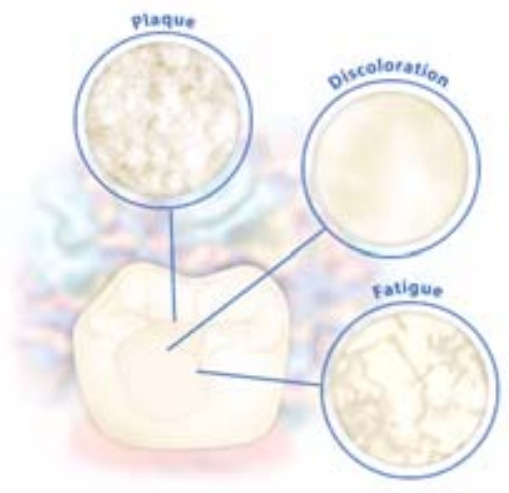

Abstract

Aim: The aim of this study was to assess the effect of repeated (twice) applications of two fluoride varnishes (Duraflor and CavityShield) on the surface micromorphology of a high-viscosity glass ionomer (Fuji IX GP), a compomer (F2000), and a flowable composite (Filtek ${ }^{\mathrm{TM}}$ Flow) using a profilometer and scanning electron microscope (SEM).

Methods and Materials: Fifteen specimens were prepared from each material, surface roughness $\left(R_{a}\right)$ was measured with a profilometer, and an impression was made for epoxy replicas. The fluoride varnishes were applied to the experimental specimens of each material at repeated intervals of 48 hours. For all specimens, $\mathrm{R}_{\mathrm{a}}$ was measured and SEM replicas were examined.

Results: The final $R_{a}$ of glass ionomer was $3.49 \pm 0.59$ (mean \pm SD) for CavityShield, $4.69 \pm 1.33$ for Duraflor, and $2.96 \pm 1.53$ for the controls. The final $R_{a}$ of flowable composite was $0.53 \pm 0.20$ for CavityShield, 2.61 \pm 3.08 for Duraflor, and $0.15 \pm 0.09$ for controls. For glass ionomer and flowable composite, Duraflor was associated with a significantly higher roughness at the final measurement compared to controls $(P<0.05)$. SEM micrographs showed differing surface topographies which in many specimens confirmed $R_{a}$ analysis.

Conclusion: Fuji IX GP and Filtek ${ }^{\mathrm{TM}}$ Flow showed significantly higher roughness after two applications of Duraflor compared to controls.

Keywords: Fluoride varnishes, surface roughness, $\mathrm{R}_{\mathrm{a}}$, glass ionomer, flowable composite, compomers

Citation: Salama FS, Schulte KM, Iseman MF, Reinhardt JW. Effects of Repeated Fluoride Varnish Application on Different Restorative Surfaces. J Contemp Dent Pract 2006 November;(7)5:054-061. 
Introduction

The effect of topical fluorides, particularly acidulated phosphate fluoride (APF) application, on restorative materials has been documented in several studies. ${ }^{1-4}$ This effect is of clinical significance because topical fluorides are recommended as a preventive strategy for children and adolescents. ${ }^{5}$ A study evaluating the surface micromorphology of resin-modified glass-ionomer cements and polyacid-modified resin composites subjected to a neutral sodium fluoride and an APF gel application showed erratic behaviors of both materials concerning their micromorphology when subjected to fluoride gel application. ${ }^{6}$ Patients with restorative materials who receive topical fluoride treatments could be at risk of increasing the surface roughness $\left(R_{a}\right)$ of the material. ${ }^{1,3,4}$ This $R_{a}$ contributes to many problems ranging from increased plaque adhesion and its harmful effects on the tooth and periodontium, to surface discoloration and fatigue failure. ${ }^{7,8}$ The amount of plaque correlates with the $R_{a}$ of various restorative materials, and the fluorides of glass-ionomers do not efficiently prevent the attachment and the viability of Streptococcus mutans. ${ }^{9}$

Fluoride varnishes are quickly becoming the topical fluoride treatment of choice. Numerous clinical trials have examined the efficacy and safety of fluoride varnishes as caries-preventive agents in both primary and permanent teeth..$^{10-12}$ As more and more clinical trials unravel the efficacy of these agents, there is little doubt fluoride varnishes will become an integral part of the preventive armamentarium in the battle against dental caries. ${ }^{13}$ Fluoride varnish needs to be reapplied to maintain its caries-preventive effect. ${ }^{14,15}$ The only disadvantage of fluoride varnishes is they cause a temporary change in tooth color and perceptible color changes in some restorative materials. ${ }^{16}$ Few studies have investigated the effect of fluoride varnishes on restorative materials. An evaluation of repeated applications of fluoride varnish on the surface of restorative materials will be valuable. Therefore, this study assessed the effect of repeated (twice) applications of two fluoride varnishes (Duraflor and CavityShield) on the surface micromorphology of a high-viscosity glass ionomer (Fuji IX GP), a compomer (F2000), and a flowable composite (Filtek ${ }^{\mathrm{TM}}$ Flow) using a profilometer and SEM.
Methods and Materials

Fifteen flat cylindrical specimens $(8 \mathrm{~mm}$ diameter, $2 \mathrm{~mm}$ thickness) were prepared from three restorative materials according to the manufacturer's instructions, using cylindrical Teflon molds. The restorative materials used were Fuji IX GP (GC America Inc., Alsip, IL, USA), F2000 (3M ESPE, St. Paul, MN, USA), and Filtek $^{\text {TM }}$ Flow (3M ESPE, St. Paul, MN, USA). The materials were expressed into the Teflon molds. Each specimen was immediately covered with a piece of celluloid material cut to size and a glass slide, clamped with a C-clamp modified in the center so the cure light could reach the specimen, and light cured at 10 millimeters distance for 40 seconds. The C-clamp, glass slide, and celluloid material were then removed and no further finishing or polishing carried out, and the specimen was again light cured for 40 seconds at a distance of 10 millimeters. Pre-treatment (initial) $R_{a}$ was measured with a profilometer (Mitutoyo Surftest, Mitutoyo Corporation, Japan). An impression of each specimen was taken using an injectable polyvinylsiloxane (GC America Inc.). The specimens were removed from the impression material after 15 minutes and were allowed to degas for one hour before making replicas. Epoxy replicas of the specimens were prepared in the impressions using Buehler Epoxicure Resin (Epoxide, Buehler, Lake Bluff, IL, USA) and allowed to set for 24 hours before separation. The specimens were then stored for seven days in distilled water at $37^{\circ} \mathrm{C}$ before initiating surface treatment. The two fluoride varnishes used for surface treatment were Duraflor (Pharmascience, Inc., Montreal, Quebec, Canada) and Cavity Shield (Omnii Products, West Palm Beach, FL, USA). Three main groups (15 molds each) comprised of the three restorative materials were further subdivided into subgroups based on the treatment conditions, five each for control (no treatment), Duraflor application, and Cavity Shield application (Table 1).

The fluoride varnishes were applied according to the manufacturer's instructions and were left on the specimens for four hours. The varnish was removed from the surface of each specimen with a stream of high-pressure tap water and 20 swipes with a standard dental cotton roll. The specimens were allowed to air dry and a second set of $R_{a}$ values were obtained (post 
Table 1. Groups/subgroups, materials, and surface treatment used in the present study.

\begin{tabular}{|c|c|c|}
\hline Group Number & Material & Surface Treatment \\
\hline 1a & Fuji IX GP & Control-no treatment \\
\hline $1 \mathrm{~b}$ & Fuji IX GP & Duraflor before treatment \\
\hline $1 \mathrm{C}$ & Fuji IX GP & CavityShield before treatment \\
\hline $2 a$ & F2000 & Control-no treatment \\
\hline $2 \mathrm{~b}$ & F2000 & Duraflor before treatment \\
\hline $2 c$ & F2000 & CavityShield before treatment \\
\hline $3 a$ & Filtek ${ }^{\mathrm{TN}}$ Flow & Control-no treatment \\
\hline $3 b$ & Filtek ${ }^{\text {TN }}$ Flow & Duraflor before treatment \\
\hline $3 \mathrm{c}$ & Filtek ${ }^{\text {TM }}$ Flow & CavityShield before treatment \\
\hline
\end{tabular}

treatment 1). Impressions were completed; the specimens were returned to the distilled water in the closed container at $37^{\circ} \mathrm{C}$. After 48 hours, they were removed and a second four-hour treatment of varnish was applied. $R_{a}$ values were obtained (post treatment 2) and impressions were completed. For the control group, the same steps were taken; this included the washing with water and 20 swipes of the cotton roll and $R_{a}$ values obtained at the three time periods, but fluoride varnish was not applied. All the replicas were mounted on aluminum stubs and sputter-coated with gold palladium. Careful examination of the replicas was performed using a scanning electron microscope (SEM) at an operating magnification ranging from X200 to 2000 and an accelerating voltage of $10 \mathrm{KV}$. Micrographs/digital images were taken at the center of each replica and of representative areas at X1000 to evaluate the surface texture characteristics of all subgroups. The photomicrographs of all specimens were examined, and the surface texture was evaluated for the presence and degree of visual changes in the surface texture of each control and experimental specimen of the three restorative materials according to certain criteria of the surface texture. ${ }^{17}$ Statistical analysis was conducted using analysis of variance (ANOVA) followed by Fisher's Least Significant Difference test for pairwise comparisons to compare the two fluoride varnishes, the control of each material versus each other, the control versus one application for each material, and two applications versus each other.

\section{Results}

The control specimens (no treatment) of F2000 showed the lowest $R_{a}$ value (Mean $\left.\pm S D\right)(0.17 \pm$
$0.76)$, followed by Filtek ${ }^{\mathrm{TM}}$ Flow $(0.36 \pm 0.23)$, and Fuji IX GP (1.98 \pm 2.10$)$. The final $R_{a}$ (following two applications of the fluoride varnish) of F2000 was $1.16 \pm 1.28$ for CavityShield, $0.63 \pm 0.99$ for Duraflor, while the control was $0.30 \pm 0.36$. The $R_{a}$ evaluations in microns (Mean $\pm S D$ ) for materials/treatments are shown in Table 2. The final $R_{a}$ of Fuji IX GP was $3.49 \pm 0.59$ for CavityShield, $4.69 \pm 1.33$ for Duraflor, and 2.96 \pm 1.53 for the controls. The final $R_{a}$ of Filtek ${ }^{\mathrm{TM}}$ Flow was $0.53 \pm 0.20$ for CavityShield, $2.61 \pm$ 3.08 for Duraflor, and $0.15 \pm 0.09$ for the controls. ANOVA showed a significant difference between materials, fluoride varnishes, and repeated applications. Post-hoc tests on materials and fluoride varnishes indicated Fuji IX GP differed significantly from either F2000 or Filtek ${ }^{\mathrm{TM}}$ Flow, but the latter two did not differ significantly from each other. The control (no treatment) $R_{a}$ was significantly different from either the first or final roughness score of each material, which do not differ from each other. For Fuji IX GP and Filtek ${ }^{\mathrm{TM}}$ Flow, Duraflor was associated with a significantly higher roughness at the final measurement compared to the control $(P<0.05)$. Examination of replicas for all materials and surface treatments and assessment of SEM micrographs showed differing surface topographies which in many specimens confirmed $R_{a}$ analysis. The surface texture varied from smooth homogenous texture to slight or moderate roughness with pits, voids, cracks grooves, and projections. Representative surfaces of Fuji IX GP and Filtek Flow initial control, control after two cycles of washing/no varnish, after the first application of Duraflor, and then after the 2nd application of Duraflor are shown in Figures 1-8. 
Table 2. Surface roughness $\left(R_{a}\right)$ in microns for materials/treatments (mean $\pm S D$ ).

\begin{tabular}{|l|l|c|c|c|}
\hline $\begin{array}{c}\text { Restorative } \\
\text { Material }\end{array}$ & \multicolumn{1}{|c|}{$\begin{array}{c}\text { Surface } \\
\text { Treatment }\end{array}$} & $\begin{array}{c}\text { Time 0 } \\
\text { (initial reading - } \\
\text { before treatment) }\end{array}$ & $\begin{array}{c}\text { Time 1 } \\
\text { (after 1st treatment } \\
\text { application) }\end{array}$ & $\begin{array}{c}\text { Time 2 } \\
\text { (after 2nd treatment } \\
\text { application) }\end{array}$ \\
\hline Fuji IX GP & CavityShield & $2.6 \pm 2.50$ & $3.94 \pm 1.23$ & $3.49 \pm 0.59$ \\
\hline Fuji IX GP & Duraflor & $2.87 \pm 2.31$ & $4.6100 \pm 1.66$ & $4.69 \pm 1.33$ \\
\hline Fuji IX GP & $\begin{array}{l}\text { No treatment } \\
\text { (control) }\end{array}$ & $1.98 \pm 2.10$ & $3.82 \pm 2.52$ & $2.96 \pm 1.53$ \\
\hline F2000 & CavityShield & $0.52 \pm 0.44$ & $0.77 \pm 0.35$ & $1.16 \pm 1.28$ \\
\hline F2000 & Duraflor & $0.66 \pm 1.10$ & $1.02 \pm 1.02$ & $0.63 \pm 0.99$ \\
\hline F2000 & $\begin{array}{l}\text { No treatment } \\
\text { (control) }\end{array}$ & $0.17 \pm 0.75$ & $0.15 \pm 0.06$ & $0.30 \pm 0.36$ \\
\hline Filtek ${ }^{\mathrm{TM}}$ Flow & CavityShield & $0.17 \pm 0.63$ & $0.56 \pm 0.24$ & $0.53 \pm 0.20$ \\
\hline Filtek ${ }^{\mathrm{TM}}$ Flow & Duraflor & $0.17 \pm 0.60$ & $1.52 \pm 2.05$ & $2.61 \pm 3.08$ \\
\hline Filtek ${ }^{\mathrm{TM}}$ Flow & $\begin{array}{l}\text { No treatment } \\
\text { (control) }\end{array}$ & $0.36 \pm 0.23$ & $0.23 \pm 0.16$ & $0.15 \pm 0.09$ \\
\hline
\end{tabular}

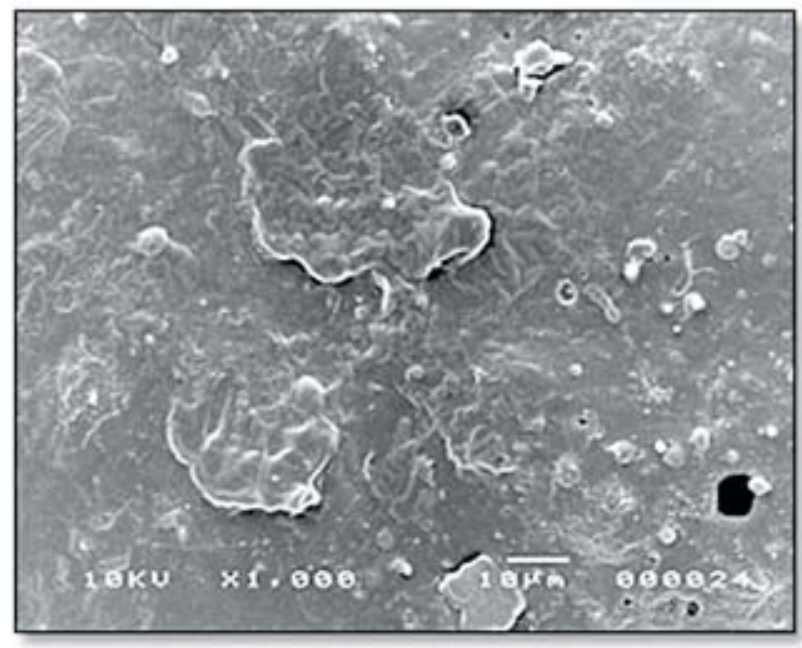

Figure 1. Scanning electron micrograph of Fuji IX GP initial control (1000x).

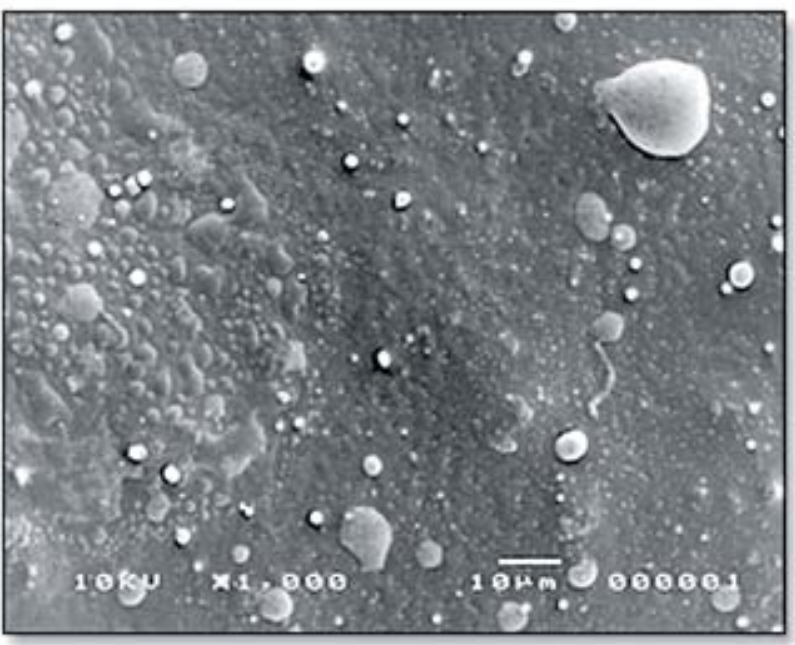

Figure 3. Scanning electron micrograph of Fuji IX GP control after two cycles of washing/no varnish (1000x).

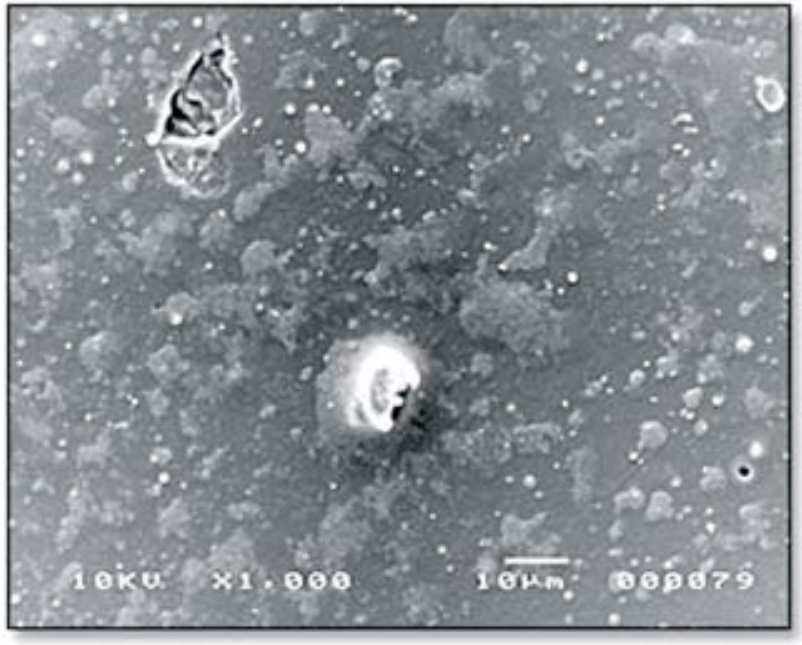

Figure 2. Scanning electron micrograph of Filtek Flow Initial Control (1000x).

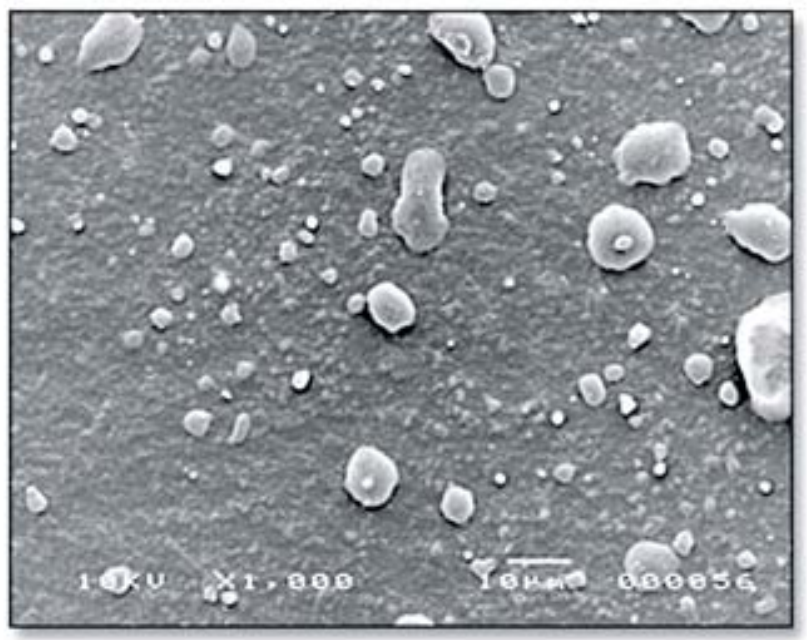

Figure 4. Scanning electron micrograph of Filtek Flow Control after two cycles of washing/no varnish (1000x). 


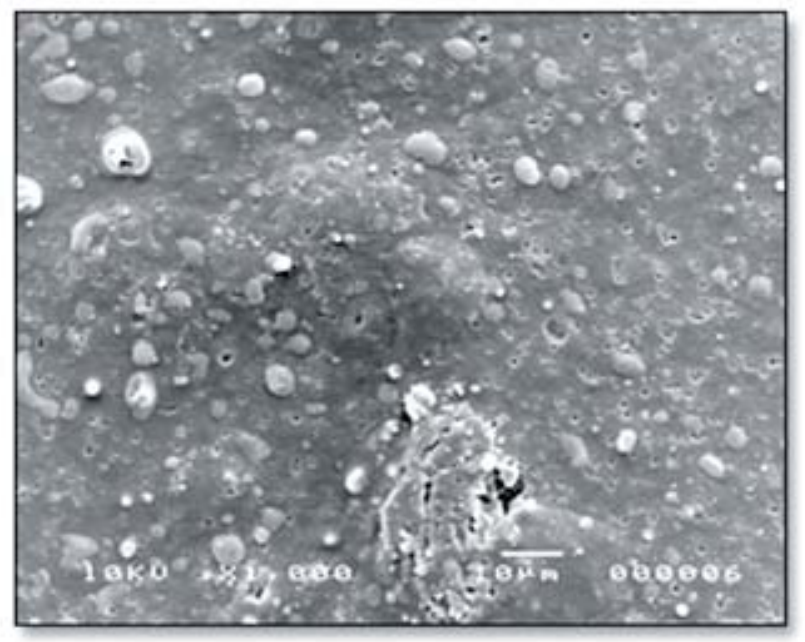

Figure 5. Scanning electron micrograph of Fuji IX GP 1st application of Duraflor (1000x).

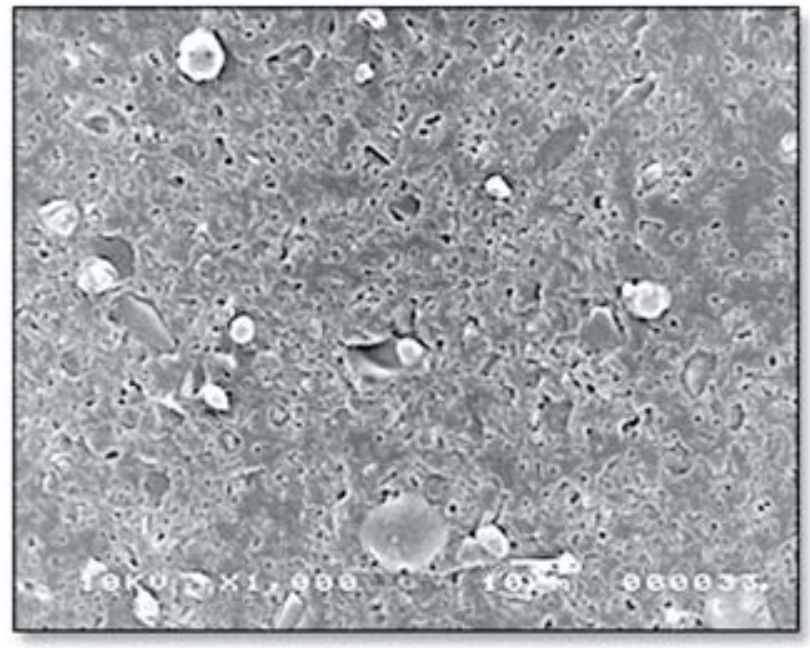

Figure 7. Scanning electron micrograph of Fuji IX GP 2nd application of Duraflor (1000x).

\section{Discussion}

The effect of fluoride varnishes on the surface characteristics of restorative materials has received little, if any, attention. Therefore, the hypothesis of this study was to determine whether repeated applications of commercially available fluoride varnishes causes any micromorphological effect on the surface of some restorative materials in vitro. The micromorphological effect in the form of surface texture was measured both qualitatively and quantitatively. We chose to use three different types of restorative materials (Fuji IX GP, F2000, and Filtek ${ }^{\mathrm{TM}}$ Flow) because many clinicians use a variety of materials in their daily practice, and the application of APF gel did not increase $R_{a}$ of some light-cured materials. ${ }^{3}$ Similar to another

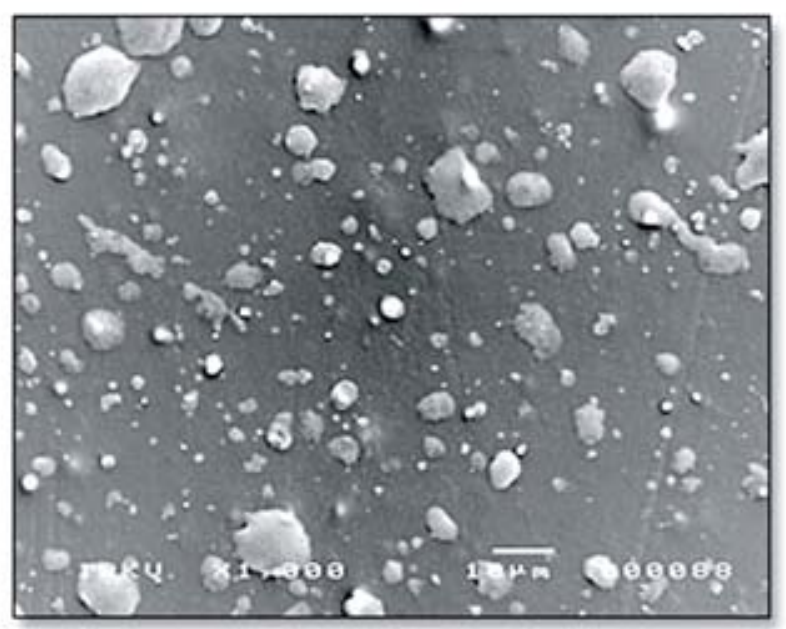

Figure 6. Scanning electron micrograph of Filtek Flow 1st application of Duraflor (1000x).

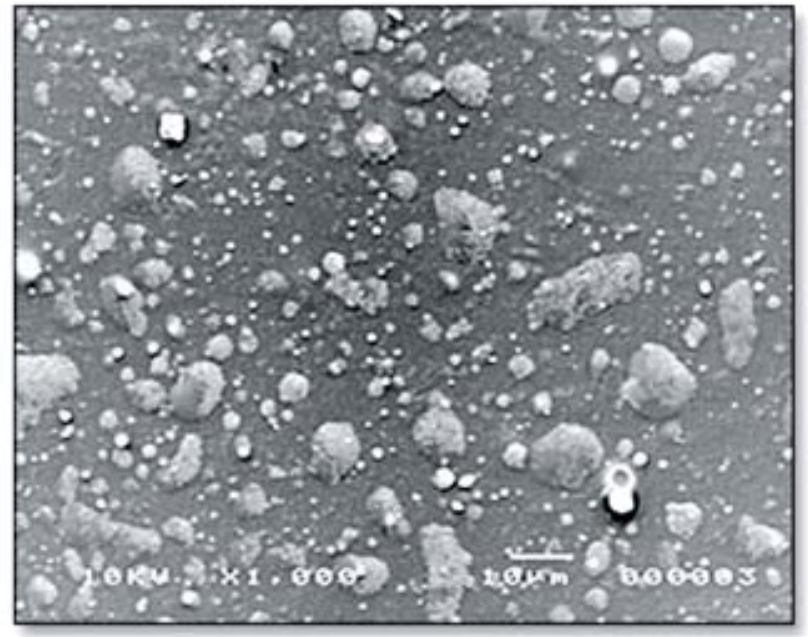

Figure 8. Scanning electron micrograph of Filtek Flow 2nd application of Duraflor (1000x).

study $^{3}$ which used repeated applications of APF, the present study used repeated applications of fluoride varnishes to simulate clinical application of the materials. The present study found $R_{a}$ of Fuji IX GP and Filtek ${ }^{T M}$ Flow was significantly higher after the final application of Duraflor fluoride varnish when compared to the control. El-Badrawy and $\mathrm{McComb}^{18}$ found APF has a deleterious effect on resin-modified glass ionomers and a polyacidmodified composite resin, while minimal effects resulted from the sodium fluoride gel compared to the control group. The present study showed the control (no treatment) $R_{a}$ was significantly different from either the first or final roughness score of each material, which do not differ from each 


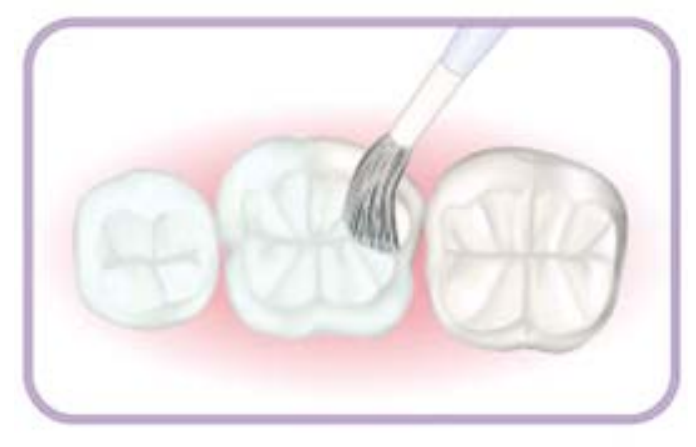

other. Similar findings on different restorative materials using APF gel was reported by Setty et al. ${ }^{19}$ who showed a significant increase of the $\mathrm{R}_{\mathrm{a}}$ and decreased surface microhardness of all tested materials, which was pronounced in conventional glass ionomers when compared with resin modified glass ionomers and compomers. The same study ${ }^{19}$ also reported sodium fluoride and stannous fluoride produced a statistically significant increase in the $R_{a}$ of conventional glass ionomers without any significant change in $\mathrm{R}_{\mathrm{a}}$ and surface microhardness on the rest of the materials tested, except for sodium fluoride on surface microhardness values of Fuji II, which was statistically significant.

Cehreli et al..$^{3}$ evaluated the effect of repeated exposure to APF gel on the surface morphological characteristics and $R_{a}$ of high-viscosity glass ionomer, compomer, and resin-modified glassionomer cement. The authors showed among compomer materials, F2000 displayed the highest $R_{a}$ average value; while among all groups, the high-viscosity glass ionomer (Fuji IX GP) displayed the highest $R_{a}$. The present study showed Fuji IX GP, Filtek TM Flow, and Duraflor fluoride varnish were associated with significantly higher roughness at the final measurement compared to the controls. Debner et al. ${ }^{16}$ also found Duraflor and Duraphat fluoride varnishes caused perceptible color changes in compomer, hybrid ionomer, and composite after application; however, FluorProtector fluoride varnish did not affect the color of the materials. After brushing, none of the materials exhibited perceptible values except the composite with Duraflor.

The present study found only Duraflor produced a significant increase in $R_{a}$. We assumed this may be partially due to its apparent ability to adhere to the restorative material specimens much more tenaciously. In fact, during the course of the study, it was found Duraflor would not readily rinse off of the specimens, even with a stream of water under high pressure. Therefore, we had to improvise with cotton rolls in order to clear the surface. Had we not done this, the profilometer would have scraped through a considerable amount of varnish as it tracked across the specimen surface. That being said, one must consider there may have been remnants of the varnish material still persistently attached to the surface, which may have affected the final $R_{a}$ values of the Duraflor specimens. However, examination and assessment of SEM replicas in the present study confirmed the data obtained from $R_{a}$ analysis. Although adherence of fluoride varnishes to tooth structure and restorative materials can be a beneficial feature for prolonged fluoride exposure in vivo, it makes it difficult to do an in vitro surface evaluation study. Therefore, we used a $R_{a}$ analyzer in the form of an arithmetic mean to determine the quantitative value of texture and SEM photomicrograph to evaluate $R_{a}$ quantitatively. Kula et al. ${ }^{1}$ determined by visual inspection and by SEM whether APF and neutral sodium fluoride agents cause surface roughening of unfilled resins sealants, filled resins sealants, and glass-ionomer sealants. The authors found filled sealants and the glassionomer sealants exhibited visually apparent changes depending on the treatment and SEM inspection of filled sealants with visually apparent changes showing loss of filler particles, whereas the glass-ionomer sealants exhibited apparent destruction both of the matrix and the filler particle.

Fluoride varnish needs to be reapplied to maintain its caries-preventive effect. ${ }^{14,15}$ Fluoridecontaining varnishes improve the shortcomings of existing topical fluoride vehicles by prolonging contact of the fluoride with tooth enamel. ${ }^{20}$ Various application schedules have been proposed and semi-annual application has been tested most often. ${ }^{20-22}$ Intensive treatment protocols using three applications of Duraphat in one week per year over three and four years showed caries reductions of $46 \%$ to $67 \%$ in proximal surfaces. ${ }^{23-25}$ Applying fluoride-release varnish three times in a single week produced greater and longer release of fluoride than did one application. ${ }^{26}$ The varnish remains on the 
tooth surface for several hours; microscopic evaluations of the enamel surface have shown small blocks of varnish remain attached to enamel even after in vitro demineralization challenge and sonication. ${ }^{27}$ As more fluoride varnishes are available in the market and with prolonging contact to tooth enamel and restorative materials, more studies should be performed in order to fully determine whether or not surface etching is occurring and whether or not there are any clinical effects and implications. However, the positive aspects of fluoride varnish previously mentioned should be considered and may outweigh the negative effects of the etching, especially in high-risk individuals for dental caries.

\section{Conclusions}

Based on the methodology used in this study we could conclude:

1. Fuji IX GP exhibited significantly higher initial $R_{a}$, in the form of an arithmetic mean value, than F2000 or Filtek ${ }^{\text {TM }}$ Flow.

2. No significant difference was found in the initial $R_{a}$ between F2000 and Filtek ${ }^{T M}$ Flow.

3. Fuji IX GP and Filtek ${ }^{\text {TM }}$ Flow showed significantly higher roughness after two applications of Duraflor compared to the controls.

4. The surface texture of all materials varied from smooth homogenous texture to slight or moderate roughness with pits, voids, cracks, grooves, and projections.

\section{References}

1. Kula K, Thompson V, Kula T, Nelson S, Selvaggi R, Liao R. In vitro effect of topical fluorides on sealant materials. J Esthet Dent 1992; 4: 121-127.

2. Salama FS, EI-Mallakh B. Effect of APF gel application on the surface microhardness of lightactivated restorative materials. The Saudi Dent J 1996; 8: 81-86.

3. Cehreli ZC, Yazici R, Garcia-Godoy F. Effect of 1.23 percent APF gel on fluoride-releasing restorative materials. ASDC J Dent Child 2000; 67: 330-337.

4. Soeno K, Matsumura H, Atsuta M, Kawasaki K. Influence of acidulated phosphate fluoride agent and effectiveness of subsequent polishing on composite material surfaces. Oper Dent 2002; 27: 305-310.

5. Petersson GH, Bratthall D. The caries decline: a review of reviews. Eur J Oral Sci 1996; 104: 436-443.

6. Turssi CP, de Magalhaes CS, Serra MC. Effect of fluoride gels on micromorphology of resin-modified glass-ionomer cements and polyacid-modified resin composites. Quintessence Int 2001; 32: 571-577.

7. Weitman RT, Eames WB. Plaque accumulation on composite surfaces after various finishing procedures. J Am Dent Assoc 1975, 91: 101-106.

8. Adamczyk E, Spiechowicz E. Plaque accumulation on crowns made of various materials. Int $J$ Prosthodont 1990; 3: 285-291.

9. Eick S, Glockmann E, Brandl B, Pfister W. Adherence of Streptococcus mutans to various restorative materials in a continuous flow system. J Oral Rehabil 2004; 31: 278-28.

10. Holm AK. Effect of a fluoride varnish (Duraphat) in preschool children. Community Dent Oral Epidemiol 1979; 7: 241-245.

11. Weinstein P, Domoto P, Koday M, Leroux B. Results of a promising open trial to prevent baby bottle tooth decay: a fluoride varnish study. ASDC J Dent Child 1994; 61: 338-341.

12. Petersson LG, Twetman S, Pakhomov GN. The efficiency of semiannual silane fluoride varnish applications: a two-year clinical study in preschool children. J Public Health Dent 1998; 58: 57-60.

13. Vaikuntam J. Fluoride varnishes: should we be using them? Pediatr Dent 2000; 22: 513-516.

14. Seppä L. Fluoride content of enamel during treatment and 2 years after discontinuation of treatment with fluoride varnishes. Caries Res 1984; 18: 278-281.

15. Seppä L, Tuutti H, Luoma H. Post-treatment effect of fluoride varnishes in children with a high prevalence of dental caries in a community with fluoridated water. J Dent Res 1984; 63: 1221-1222.

16. Debner T, Warren DP, Powers JM. Effects of fluoride varnish on color of esthetic restorative material. J Esthet Dent 2000; 12: 160-163. 
17. Salama FS. Surface roughness of resin sealants and compomer materials. Egyptian Dent J 1996; 42: 1807-1816.

18. El-Badrawy WA, McComb D. Effect of home-use fluoride gels on resin-modified glass-ionomer cements. Oper Dent 1998; 23: 2-9.

19. Setty JV, Singh S, Subba Reddy VV. Comparison of the effect of topical fluorides on the commercially available conventional glass ionomers, resin modified glass ionomers and polyacid modified composite resins--an in vitro study. J Indian Soc Pedod Prev Dent. 2003; 21: 55-69.

20. Beltran-Aguilar ED, Goldstein JW, Lockwood SA. Fluoride varnishes: A review of their clinical use, cariostatic mechanism, efficacy and safety. J Am Dent Assoc 2000; 13: 589-596.

21. Seppa L. Studies of fluoride varnishes in Finland. Proc Finn Dent Soc 1991; 87: 541-547.

22. Arnbjerg D. Use of professionally administered fluoride among Danish children. Acta Odontol Scand. 1992; 50: 289-293.

23. Petersson LG, Maki Y, Twetman S, Edwardsson S. Mutans streptococci in saliva and interdental spaces after topical applications of an antibacterial varnish in schoolchildren. Oral Microbiol Immunol. 1991; 6: 284-287.

24. Petersson LG, Arthursson L, Ostberg C, Jonsson G, Gleerup A. Caries-inhibiting effects of different modes of Duraphat varnish reapplication: a 3-year radiographic study. Caries Res. 1991; 25: 70-73.

25. Skold L, Sundquist B, Eriksson B, Edeland C. Four-year study of caries inhibition of intensive Duraphat application in 11-15-year-old children. Community Dent Oral Epidemiol. 1994; 22: 8-12.

26. Castillo JL, Milgrom P. Fluoride release from varnishes in two in vitro protocols. J Am Dent Assoc. 2004; 135: 1696-1699.

27. Sorvari R, Meurman JH, Alakuijala P, Frank RM. Effect of fluoride varnish and solution on enamel erosion in vitro. Caries Res 1994; 28: 227-232.

\section{About the Authors}
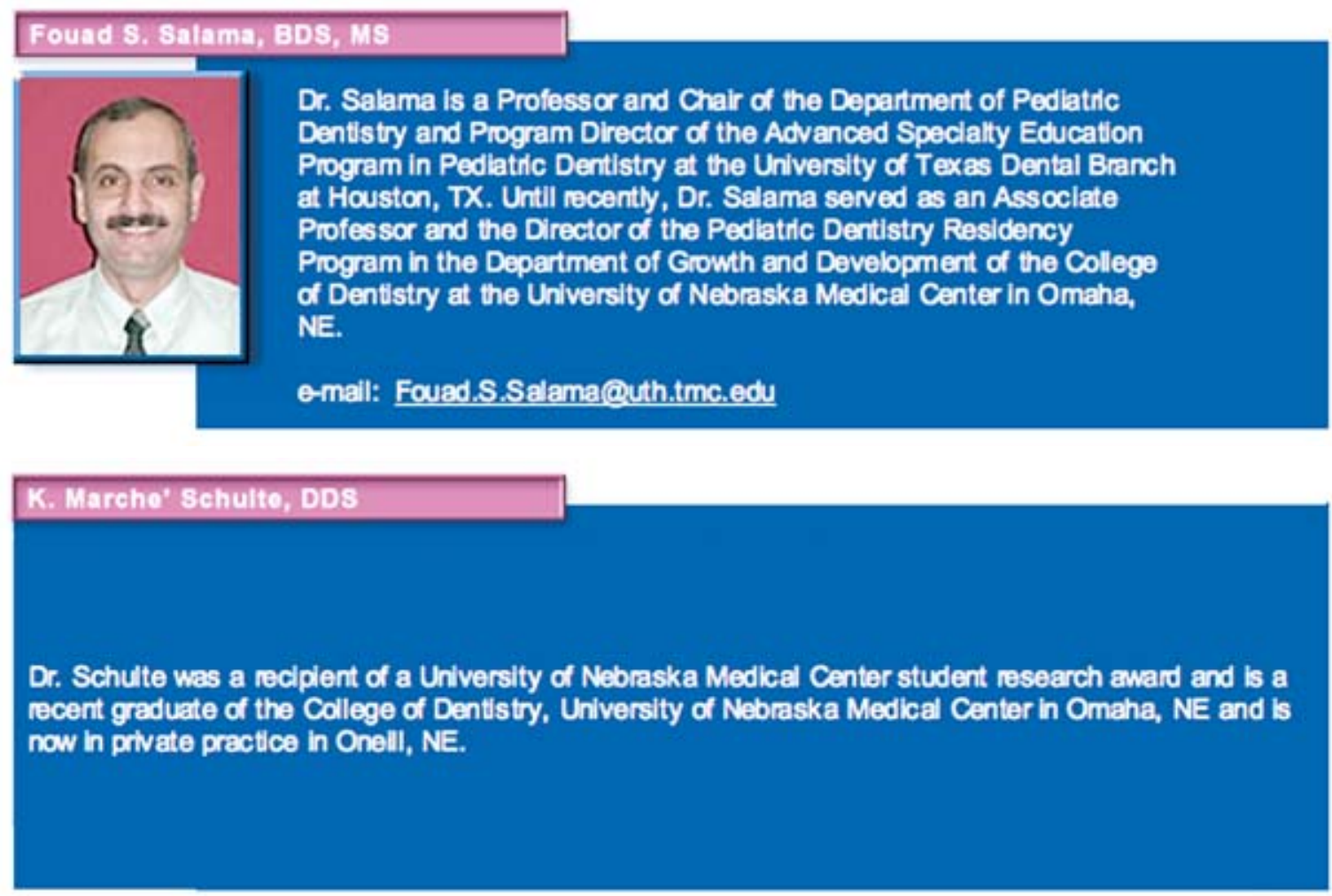

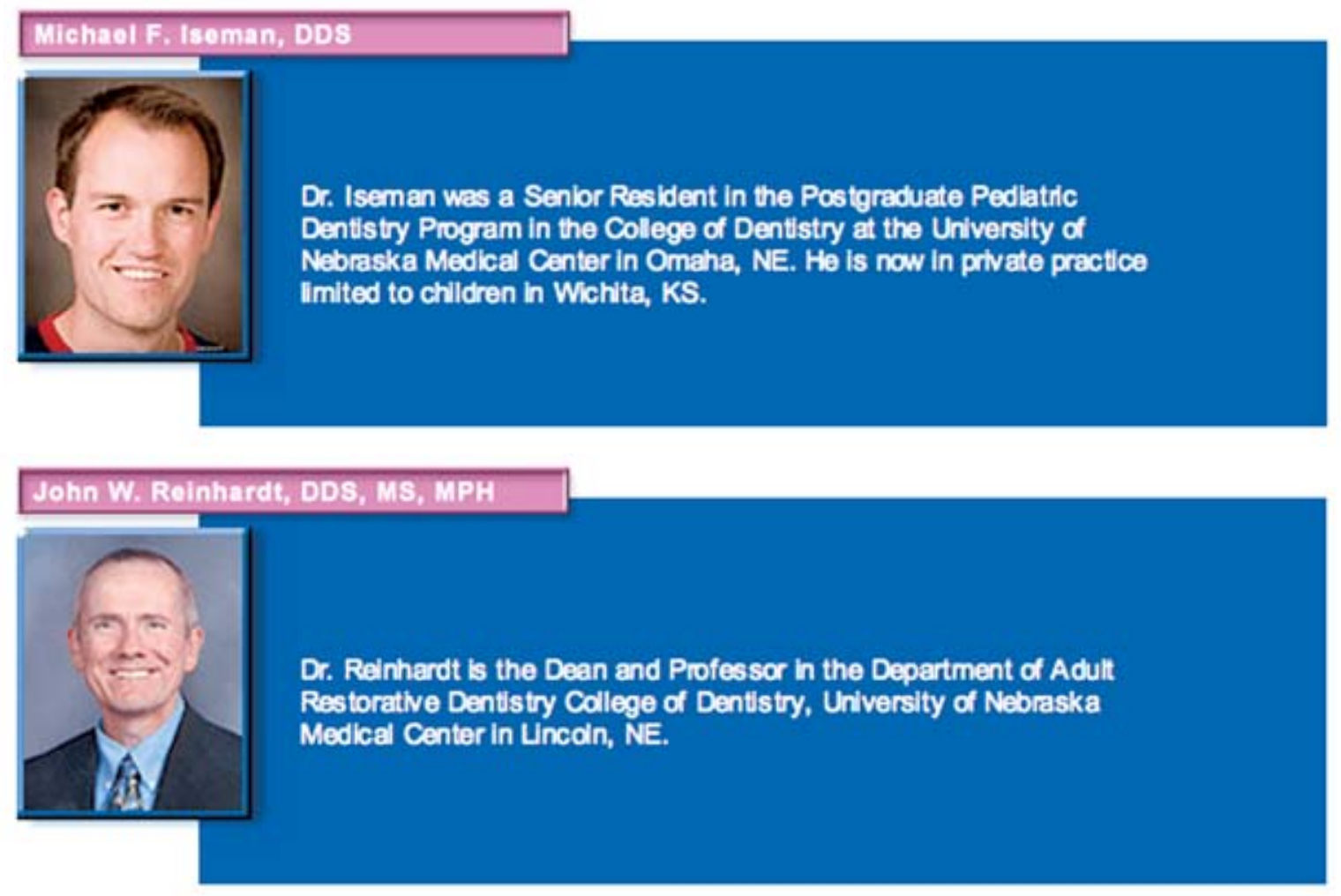

\section{Acknowledgement}

This study was supported by the University of Nebraska Medical Center, College of Dentistry, Student Summer Research Award FY\# 04-06. 